\title{
Mechanism of Ancrod Anticoagulation
}

\section{A DIRECT PROTEOLYTIC EFFECT ON FIBRIN}

\author{
Salvatore V. Pizzo, Martin L. Schwartz, Robert L. Hill, and \\ PAtrick A. McKeE \\ From the Department of Biochemistry, Duke University Medical Center, ana \\ the Department of Medicine, Veterans Administration Hospital, \\ Durham, North Carolina 27710
}

\begin{abstract}
A B S T R A C T Fibrin formed in response to ancrod, reptilase, or thrombin was reduced by $\beta$-mercaptoethanol and examined by sodium dodecyl sulfate polyacrylamide gel electrophoresis. It was found that ancrod progressively and totally digested the $\alpha$-chains of fibrin monomers at sites different than plasmin; however, further digestion of fibrin monomers by either reptilase or thrombin was not observed. Highly purified ancrod did not activate fibrin-stabilizing factor (FSF); however, the reptilase preparation used in these experiments, like thrombin, activated FSF and thereby promoted cross-link formation. Fibrin, formed by clotting purified human fibrinogen with ancrod, reptilase, or thrombin for increasing periods of time in the presence of plasminogen, was incubated with urokinase and observed for complete lysis. Fibrin formed by ancrod was strikingly more vulnerable to plasmin digestion than was fibrin formed by reptilase or thrombin. The lysis times for fibrin formed for $2 \mathrm{hr}$ by ancrod, reptilase, or thrombin were 18,89 , and $120 \mathrm{~min}$, respectively. Evidence was also obtained that neither ancrod nor reptilase activated human plasminogen. These results indicate that fibrin formed by ancrod is not cross-linked and has significantly degraded $\alpha$-chains; as expected, ancrodformed fibrin is markedly susceptible to digestion by plasmin.
\end{abstract}

\section{INTRODUCTION}

Ancrod (Arvin) ${ }^{1}$ and reptilase ${ }^{2}$ are the purified coagulant enzymes which can be isolated from the crude venoms

Mr. Pizzo and Mr. Schwartz are predoctoral Fellows, Medical Scientist Training Program, National Institute of General Medical Sciences, National Institutes of Health (5T05-GM 01678-05). Dr. McKee is a Clinical Investigator, Durham Veterans Administration Hospital.

Received for publication 3 April 1972 and in revised form 18 July 1972.

${ }^{1}$ Arvin is the registered trademark of Twyford Laboratories, Ltd., London. of the Malayan (Agkistrodon rhodostoma) and South American (Bothrops atrox) pit vipers, respectively (1, 2 ). Both purified coagulants are known to cause a marked lowering of the plasma fibrinogen by converting it to fibrin which in turn, is assumed to be rapidly digested by plasmin before significant vascular occlusion and organ dysfunction occur (3-10). Of the two preparations, ancrod has been more extensively studied in humans, and to date, there appears to be very few thrombotic, hemorrhagic, or allergic complications associated with its use $(5,6,11-17)$. As a result of such observations, attention has been focused on these two venom enzymes for their potential usefulness in acute thromboembolic disorders.

Both enzymes act similarly to thrombin by catalyzing the formation of a fibrin clot when added to whole plasma or solutions of purified fibrinogen $(1,18-20)$. Thrombin cleaves fibrinopeptides $A$ and $B$ from the amino termini of the $\alpha(\mathrm{A})$ - and $\beta(\mathrm{B})$-chains of fibrinogen, respectively, whereas ancrod and reptilase cleave only fibrinopeptide A from the $\alpha(\mathrm{A})$-chains (21-23). Ancrod does not appear to activate fibrin-stabilizing factor $(\mathrm{FSF})^{3}$ and therefore promotes the formation of only soluble, noncross-linked fibrin (24); however, data for reptilase suggest that it does activate FSF and thus initiates insoluble, cross-linked fibrin formation (25). Until recently (26-28) it was believed that ancrod or reptilase cleaved only fibrinopeptide A from fibrinogen and that neither enzyme exerted any further direct proteolytic effect on the fibrin monomer $(22,24,29)$. Furthermore, results of other investigators suggested that neither of the enzymes affects other clotting factors and neither activate plasminogen $(6,15,19,29)$. Thus, to date, the in vivo fibrinogenopenic effect of ancrod has been attributed to

\footnotetext{
"Supplied as Defibrase, Pentapharm, Ltd., Basel, Switzerland.

${ }^{3}$ Abbreviations used in this paper: FSF, fibrin-stabilizing factor; SDS, sodium dodecyl sulfate.
} 
intravascular fibrin formation which in turn evokes an enhanced blood fibrinolytic state $(4,6,12,30)$. Both the increased fibrinolysis and the reticuloendothelial system are thought to be important in the clearance of such intravascular fibrin (31). Because increased clinical use is anticipated, studies aimed at defining or clarifying the mechanisms of action of these enzymes seemed essential.

In the studies which we wish to report here, polyacrylamide gel electrophoresis in the presence of sodium dodecyl sulfate (SDS) has been used to study fibrin formed when ancrod, reptilase, or thrombin was added to purified human fibrinogen. This technique has also been used to determine if ancrod or reptilase activates highly purified FSF and plasminogen. In addition, the degradation of ancrod-, reptilase-, and thrombin-formed fibrin by plasmin has been studied. Besides releasing fibrinopeptide $\mathrm{A}$, it was found that ancrod, unlike reptilase, markedly degraded the $\alpha$-chains of fibrin monomers and thereby significantly increased the susceptibility of such fibrin to digestion by plasmin. Neither enzyme appeared to have a direct proteolytic effect on previously formed cross-linked fibrin.

\section{METHODS}

Rcagents. Human fibrinogen, fraction I-2 (95\% clottable), was prepared by the method of Blombäck and Blombäck from fresh frozen plasma (32). After purification, this fibrinogen still contained sufficient FSF to yield fully crosslinked fibrin (33). Human thrombin, kindly supplied by Dr. D. L. Aronson, Division of Biological Standards, National Institutes of Health, was dissolved in $0.05 \mathrm{~m}$ Tris $\cdot \mathrm{HCl}$ $0.15 \mathrm{M}$ sodium chloride, $\mathrm{pH} 7.4$, buffer (hereafter referred to as tris buffer) to give a concentration of $25 \mathrm{NIH} \mathrm{U} / \mathrm{ml}$ and stored at $4^{\circ} \mathrm{C}$. Purified human FSF was prepared as recently reported (34) and was dialyzed into $0.005 \mathrm{M}$ Tris · $\mathrm{HCl}-0.0001$ M EDTA, $\mathrm{pH} 7.5$, buffer and then diluted to give an absorbance of 1.0 at $280 \mathrm{~nm}$. Urea-treated fibrinogen was prepared as previously described (35), except that the concentration of fibrinogen was $5 \mathrm{mg} / \mathrm{ml}$ in tris buffer. This solution was then stored at $-20^{\circ} \mathrm{C}$. Human plasminogen was prepared according to the method of Deutsch and Mertz (36). Plasminogen purified by this method showed a SA of 20 CTA U/absorbance $U$ at $280 \mathrm{~nm}$. After chromatography the protein was dialyzed extensively against distilled water to remove salt, lyophilyzed, and stored at $-20^{\circ} \mathrm{C}$. In this preparation no autoactivation could be detected even after $1 \mathrm{yr}$ as judged by SDS-gel electrophoresis of reduced plasminogen. For use in this study a $2.0 \mathrm{mg} / \mathrm{ml}$ plasminogen solution was prepared in tris buffer and used immediately as described below. Human urokinase (Calbiochem, San Diego, Calif.) was dissolved in tris buffer to give a final concentration of 460 Ploug $\mathrm{U} / \mathrm{ml}$ and stored at $-20^{\circ} \mathrm{C}$.

In several studies freshly collected whole plasma was used. Either heparin or $3.5 \%$ sodium citrate was used as the anticoagulant for the blood samples. The blood samples were immediately centrifuged at $2000 \mathrm{~g}$ for $20 \mathrm{~min}$ after which the plasma was removed and used immediately. No spontaneous clotting was observed in plasma containing either type of anticoagulant during the course of the experiments (at least an $8 \mathrm{hr}$ observation period). A solution of reptilase (Pentapharm, Ltd.) was used as supplied. The addition of $40 \mu \mathrm{l}$ of this solution to $1 \mathrm{ml}$ of either heparin or citrate-anticoagulated plasma gave a clotting time of about $170 \mathrm{sec}$. Three different ancrod preparations were used and will be designated as follows: ancrod 1 (structurally pure) was supplied as a $67 \mathrm{U} / \mathrm{ml}$ solution with a $\mathrm{SA}$ of $1500 \mathrm{U} / \mathrm{absorbance}$ unit at $280 \mathrm{~nm}$; ancrod 2 contained $100 \mathrm{U} / \mathrm{ml}$ at a SA of $1500 \mathrm{U} /$ absorbance unit; and ancrod 3 , which was a further purified preparation of ancrod 2 , contained $1600 \mathrm{U} / \mathrm{ml}$ at a SA of $2200 \mathrm{U} /$ absorbance unit.

Fibrin formation by thrombin, ancrod, and reptilase. Studies were performed with purified fibrinogen which contained FSF and urea-treated fibrinogen which lacked FSF activity. In either case a stock solution of fibrinogen containing $5 \mathrm{mg} / \mathrm{ml}$ was prepared in tris buffer. Portions of $0.2 \mathrm{ml}$ were then clotted by one of the following reagents: $20 \mu 1$ of purified human thrombin, $25 \mu 1$ of reptilase, $15 \mu 1$ of ancrod 1, $10 \mu \mathrm{l}$ of ancrod 2 , or $5 \mu \mathrm{l}$ of ancrod 3 . Where indicated, $5 \mu \mathrm{l}$ of $0.8 \mathrm{~m}$ calcium chloride was added to the fibrinogen solution before the addition of one of the above enzymes. After mixing, the tubes were allowed to stand for the following time periods: $0,5,10,15,30,60,120,240$, $480,720 \mathrm{~min}$, and $24 \mathrm{hr}$. At the end of the incubation times the fibrin was washed with a large volume of $0.15 \mathrm{M}$ sodium chloride in a Petri dish, blotted on Whatman 1 filter paper to remove as much fluid as possible, and then dissolved in $1.0 \mathrm{ml}$ of $5 \mathrm{M}$ urea-2\% SDS-2\% $\beta$-mercaptoethanol in 0.01 $\mathrm{M}$ sodium phosphate buffer, $\mathrm{pH}$ 7.15. After an overnight incubation in the dispersing agent, each sample was electrophoresed on polyacrylamide gels in the presence of SDS.

Ancrod treatment of completely cross-linked fibrin. Fibrin was prepared by the addition of purified human thrombin to purified human fibrinogen as described above. In all cases, calcium chloride was present and the samples were allowed to clot for $3 \mathrm{hr}$ so that complete $\gamma$-dimerization and extensive $\alpha$-polymerization occurred (33). Following the addition of $15 \mu \mathrm{l}$ of ancrod 1 or $5 \mu \mathrm{l}$ of ancrod 3 , to each of the $0.2-\mathrm{ml}$ fibrin samples, the clot was loosened from the test tube wall and allowed to incubate for $0,5,15,30,60,120$, $240,480 \mathrm{~min}$, and $24 \mathrm{hr}$. The clots were then washed in a large volume of $0.15 \mathrm{M}$ sodium chloride, blotted, and dissolved in $1.0 \mathrm{ml}$ of $5 \mathrm{M}$ urea-2\% SDS-2\% $\beta$-mercaptoethanol -0.01 м sodium phosphate buffer, $\mathrm{pH}$ 7.15. After overnight incubation at room temperature, the samples were electrophoresed on SDS gels.

Formation of fibrin from plasma by thrombin, ancrod, and reptilase. $1-\mathrm{ml}$ portions of citrated plasma or $1-\mathrm{ml}$ portions of heparinized plasma were clotted by either $20 \mu \mathrm{l}$ of purified thrombin, $40 \mu \mathrm{l}$ of reptilase, $30 \mu 1$ of ancrod 1, 20 $\mu 1$ of ancrod 2, or $5 \mu 1$ of ancrod 3, and allowed to stand for $4 \mathrm{hr}$ at room temperature. During this time the heparinized plasma sample to which thrombin had been added did not clot. All other samples clotted in 3 min or less. Each fibrin clot was washed and blotted as described above and dissolved in $1.0 \mathrm{ml}$ of $5 \mathrm{M}$ urea-2\% SDS-2\% $\beta$-mercaptoethanol, 0.01 sodium phosphate buffer, $\mathrm{pH} 7.15$, and electrophoresed on SDS gels after overnight incubation at room temperature.

Incubation of plasminogen with thrombin, ancrod, reptilase, and urokinase. A $10 \mu \mathrm{l}$ sample of the purified plasminogen solution was treated with either $50 \mu \mathrm{l}$ of purified human thrombin, $50 \mu 1$ of reptilase, $50 \mu \mathrm{l}$ ancrod 1, $50 \mu 1$ of ancrod 2 , $10 \mu 1$ of ancrod 3 , or $20 \mu \mathrm{l}$ of urokinase. In those samples having less than $60 \mu \mathrm{l}$ total volume, tris buffer was added to make up the difference. After a $2 \mathrm{hr}$ incubation at $37^{\circ} \mathrm{C}$, the reactions were terminated by adding $60 \mu 1$ of $10 \mathrm{M}$ urea- 
$2 \% \operatorname{SDS}-2 \% \beta$-mercaptoethanol. After overnight incubation at room temperature the samples were electrophoresed.

Incubation of plasma FSF zl'mogen with thrombin, ancrod, or reptilase. The putrescine $-{ }^{14} \mathrm{C}$ assay $(37,38)$ was used to determine if the two venom enzymes activated plasma FSF. In this test, the amount of putrescine $-{ }^{14} \mathrm{C}$ (New England Nuclear, Boston, Mass.) incorporated into casein (Worthington Biochemical Corp., Freehold, N. J.) by activated FSF is quantitated. The assay was modified so that plasma FSF zymogen was preincubated with either thrombin, ancrod, or reptilase. $70 \mu \mathrm{g}$ of FSF in a volume of $200 \mu \mathrm{l}$ was incubated with either $4 \mathrm{U}$ of thrombin, $2 \mathrm{U}$ of ancrod 1, $2 \mathrm{U}$ of ancrod 2, or $3 \mathrm{U}$ of reptilase. The concentrations of thrombin, the ancrod preparations, and reptilase used in these studies were adjusted so that each gave identical clotting times when added to a standard fibrinogen solution. After incubation for $30 \mathrm{~min}$, a portion of the preincubation mixture was assayed for FSF activation as originally described $(37,38)$.

It has been shown that thrombin activates plasma FSF by cleaving a $4000 \mathrm{~mol} \mathrm{wt}$ peptide from the $a$-chain of the zymogen (34). Since this molecular weight change can be detected easily by SDS-gel electrophoresis, this method was also used to evaluate the effect of ancrod or reptilase on highly purified plasma FSF zymogen. Thus at $30 \mathrm{~min}$ and again at $120 \mathrm{~min}, 40-\mu \mathrm{l}$ portions were removed from the preincubation mixtures and were added to $40 \mu \mathrm{l}$ of $9 \mathrm{M}$ urea-2\% SDS-2\% $\beta$-mercaptoethanol in $0.01 \mathrm{M}$ sodium phosphate buffer, $\mathrm{pH} 7.1$, in order to stop the reaction and to prepare the samples for SDS-polyacrylamide gel electrophoresis.

Susceptibility of fibrin formed by thrombin, ancrod, and reptilase to plasmin degradation. Fibrin was prepared as described above using $0.2-\mathrm{ml}$ portions of fibrinogen solution with either $20 \mu \mathrm{l}$ of purified thrombin, $25 \mu \mathrm{l}$ of reptilase, or $15 \mu 1$ of ancrod 1 . Both the thrombin and reptilase clots were prepared in the presence of calcium. In these experiments, calcium was not added to the ancrod-clotting mixtures since ancrod 1 catalyzes the formation of only noncross-linked fibrin whether or not calcium is present. All samples were clotted for $5,15,30,60,120,240$, and 480 min. In addition, soluble noncross-linked fibrin was prepared by clotting urea-treated fibrinogen with thrombin for $120 \mathrm{~min}$ in the absence of calcium. At the end of the different times, each fibrin clot was dislodged from the test tube wall as $20 \mu \mathrm{l}$ of urokinase solution was added and the time required for complete clot lysis was recorded.

$S D S$-gel electrophoresis. Polyacrylamide gel electrophoresis was performed essentially as described previously (39, 40). Throughout this study $7.5 \%$ gels were used and the gel tubes were $10 \mathrm{~cm}$ in length and $0.6 \mathrm{~cm}$ in diameter. Bromophenol blue was used as a marker in all cases. A load of approximately $25 \mu \mathrm{g}$ of protein was applied to each gel. In order to calculate molecular weights, the following standards were used in each gel run (molecular weight in parentheses ): phosphorylase $A(92,500)$, transferrin $(77,000)$, albumin $(67,000)$, catalase $(60,000)$, ovalbumin $(43,000)$, pepsin $(35,000)$, and chymotrypsinogen $A(26,000)$.

\section{RESULTS}

Fibrin formation by ancrod and reptilase. Fig. 1 shows the effects of ancrod 1 on fibrinogen with time in the absence of calcium. The time course in Fig. 1 shows that the $\alpha$-chains were completely degraded and concommitantly. two bands of 38,000 and 33,000 mol wt ap-

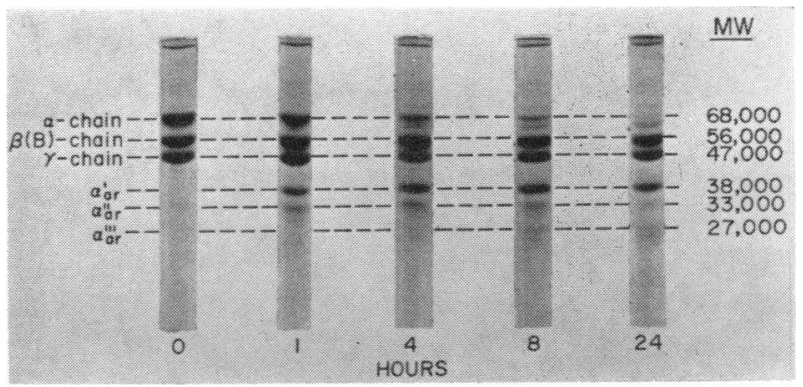

Figure 1 Reduced SDS-gel electrophoretic patterns of fibrin formed by ancrod 1 for the time periods shown beneath the gels. The $\alpha^{\prime}{ }_{\mathrm{ar}}, \alpha^{\prime \prime}{ }_{\mathrm{ar}}$, and $\alpha^{\prime \prime \prime}{ }_{\mathrm{ar}}$ are cleavage products resulting from degradation of the $\alpha$-chains by ancrod.

peared. With time, the 33,000 mol wt species underwent further degradation to the lower molecular weight species seen on the gels. Neither $\beta$-chain nor $\gamma$-chain was degraded. When calcium was included with ancrod 1 in the clotting mixture, $\gamma$-dimer and a small amount of $\alpha$-polymer formation occurred. As in the absence of calcium, however, the $\alpha$-chains of fibrin monomers were degraded by ancrod to the major cleavage products, the 38,000 and 33,000 mol wt species. When FSF-contaminated fibrinogen was clotted by ancrod 1 in the presence of calcium, it is to be emphasized that the cross-linking observed was not due to FSF activation by ancrod. Instead, this amount of cross-linking could easily be accounted for by contaminant procoagulant activity in the purified fibrinogen (41) which was demonstrated when solutions of Blombäck I-2 and I-4 purified fibrinogen clotted in 3-5 hr after the addition of calcium only. After reduction, analysis of such fibrin by SDS electrophoresis showed that by $8 \mathrm{hr}$, complete $\gamma$-dimerization, and to a lesser extent, $\alpha$-polymerization occurred. In contrast, when a FSF-activating enzyme was included in the clotting mixture, both the rate and quantity of $\gamma$-dimer and $\alpha$-polymer formation was markedly increased. Ancrod 2 gave the same degradation pattern as ancrod 1 ; however, ancrod 2 contained a contaminant, which in the presence of calcium, caused sufficient FSF activation to catalyze significant amounts of $\gamma$-dimer and $\alpha$-polymer formation at $120 \mathrm{~min}$. Ancrod 3, a more highly purified preparation of ancrod 2, caused less cross-link formation and gave results more similar to ancrod 1 .

Fig. 2 shows the gel patterns obtained when reptilase was substituted for ancrod in the presence of calcium. The first gel in Fig. 2 depicts the effect of reptilase and calcium on FSF-free fibrinogen (urea treated). From this gel, it is clear that reptilase did not directly catalyze cross-link formation between fibrin monomers. On the other hand when FSF and calcium were both present, it can be seen that cross-links formed between fibrin monomers in a manner analogous to that catalyzed by thrombin-activated FSF. While the rate of FSF activation by 


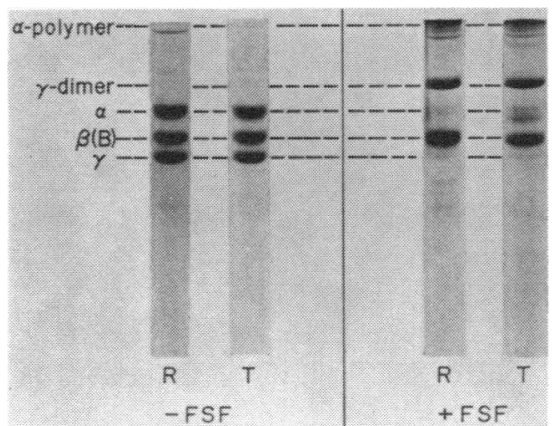

FIGURE 2 Reduced SDS-gel electrophoretic patterns of fibrin formed for $8 \mathrm{hr}$ by reptilase (R) or thrombin (T) in the presence of calcium and in the absence or presence of FSF. The first two gels show reduced reptilase-fibrin and thrombin-fibrin in the absence of FSF; no cross-linking occurred. The second two gels show that in the presence of FSF, a large amount of $\gamma$-dimer and $\alpha$-polymer formation occurred. The minor bands beneath the $\gamma$-monomer area have different mobilities than the $\alpha_{\mathrm{ar}}$-fragments, but the same mobilities as fragments lysed by plasmin.

reptilase was slightly slower since even at $10 \mathrm{~min}$, $\boldsymbol{\gamma}$-dimerization was not complete, $\alpha$-polymer formation did not appear to be significantly delayed, with maximal formation occurring at $120 \mathrm{~min}$.

It is important to note that throughout the time course of fibrin formation by reptilase, $\alpha$-chain degradation did not occur as with ancrod. Fig. 3 compares the reduced SDS-electrophoretic patterns of fibrin formed for $8 \mathrm{hr}$ by ancrod (gel $a$ ), reptilase in the absence of calcium (gel $b$ ) and reptilase in the presence of cdlcium (gel $c$ ). The final pattern (gel $d$ ) depicts the reduced digestion products which result when fibrinogen is incubated with plasmin for $15 \mathrm{~min}$ (42). In order to maximize the vis-

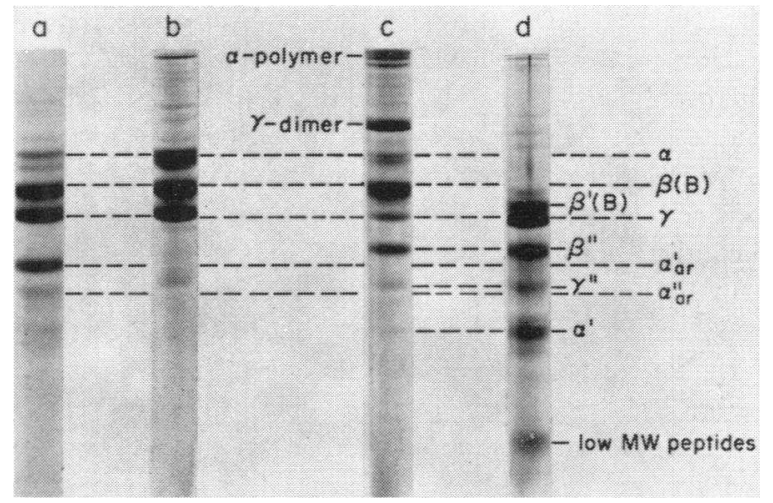

FIGURE 3 Reduced SDS-gel electrophoretic patterns of fibrin formed for $8 \mathrm{hr}$ by ancrod 1 (gel $a$ ), reptilase in the absence of calcium (gel $b$ ) and reptilase in the presence of calcium and FSF (gel $c$ ). For comparison a $15 \mathrm{~min}$ digest of fibrinogen by plasmin is shown ( minal plasmin digestion product $\beta^{\prime \prime}$ seen on gel $c$ and gel $d$ has a different mobility than the terminal ancrod digestion product $\alpha^{\prime}$ ar seen on gel $a$.

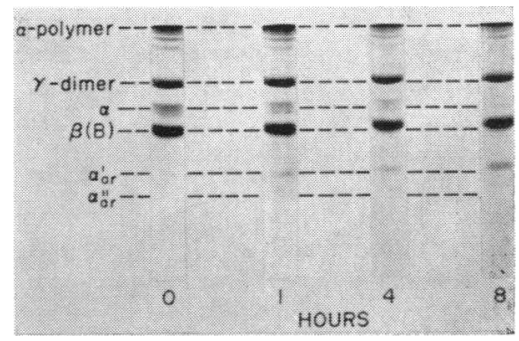

FIGURE 4 Reduced SDS-gel electrophoretic patterns of fully cross-linked fibrin which was then incubated with ancrod 1 for the time periods shown beneath each gel. The $\alpha$-chain cleavage products originate from residual $\alpha$-monomer and not $\alpha$-polymer.

ualization of cleavage products which might result from direct proteolysis of fibrin monomers by reptilase, the concentration of this enzyme in this experiment was increased 10 -fold. Under these conditions reptilase-formed fibrin showed evidence of significant degradation in the presence of calcium; however these degradation products had mobilities essentially identical with those resulting from plasmin degradation of fibrinogen. It should be noted that a $\beta^{\prime}(\mathrm{B})$-band is shown on gel $d$ which does not align with any band in the reduced pattern of the plasmin digest of reptilase-formed fibrin. This is easily explained by the fact that the $\beta^{\prime}$ (B)-band is seen only during plasmin digestion of fibrinogen; however, during plasmin digestion of any type of fibrin, whether noncross-linked or cross-linked and whether formed in response to thrombin, ancrod, or reptilase, the $\beta$-chain or $\beta(B)$-chain is degraded directly to the $\beta^{\prime \prime}$-band (43) as shown on gel $c$. In the case of ancrod, the degradation products arising during fibrin formation had mobilities that were clearly different from those resulting from fibrinogen or fibrin degradation by plasmin $(42,43)$.

Ancrod treatment of completely cross-linked fibrin. Completely cross-linked fibrin was prepared by the addition of human thrombin and calcium to fibrinogen containing contaminant FSF. These samples were then incubated with either ancrod 1 or ancrod 3 . The results were the same for both preparations. Fig. 4 shows the SDS-gel electrophoretic patterns from the experiment performed with ancrod 3 . It is apparent that $\alpha$-polymer is not degraded by ancrod. The presence of the 38,000 and 33,000 mol wt $\alpha$-chain cleavage products can be accounted for by the disappearance of the residual monomeric $\alpha$-chains which were not incorporated into the $\alpha$-polymer. Examination of $24-\mathrm{hr}$ samples still revealed $\alpha$-polymer to be present. but minimally diminished in intensity. This was due to slow fibrin degradation by trace amounts of contaminating plasmin (43) and was not due to ancrod digestion as recently suggested by other investigators (27).

Formation of fibrin from plasma by ancrod and reptilase. Table I shows the clotting times for both heparin- 
ized and citrated plasma clotted by ancrod, reptilase, or thrombin. As previously reported, heparin has little or no effect on fibrin formation in response to reptilase or ancrod $(19,20)$. Not only does heparin inhibit fibrin formation by thrombin, but it also prevents FSF activation by thrombin. Therefore the ability of ancrod or reptilase to activate plasma FSF can be tested in heparinized plasma. The SDS-gel patterns of fibrin obtained by clotting heparinized plasma with ancrod or reptilase are shown in Fig. 5. At the concentration used, thrombin did not induce clotting of the heparinized plasma even after $8 \mathrm{hr}$ and therefore no gel is shown. As can be seen all ancrod preparations degraded $\alpha$-chains in heparinized plasma. Most notably, neither $\gamma$-dimer nor $\alpha$-polymer formation was catalyzed by ancrod 1 . However both ancrod 2 and reptilase clearly promoted $\gamma$-dimer and $\alpha$-polymer formation in the presence of heparin. Ancrod 3 catalyzed only a slight amount of $\gamma$-dimer formation.

Incubation of plasminogen with thrombin, ancrod, reptilase, and urokinase. Since indirect evidence suggested that the venom enzymes do not activate plasminogen $(6,14,29)$, the effect of ancrod and reptilase on purified human plasminogen was examined. Fig. 6 shows the reduced SDS-gel electrophoretic patterns for plasminogen alone, plasminogen incubated with either thrombin, ancrod, or reptilase and plasmin formed by the action of urokinase on plasminogen. The plasminogen sample incubated with urokinase clearly shows that plasminogen activation has occurred as evidenced by the appearance of the heavy and light chains of plasmin (44). However when purified plasminogen was incubated with thrombin, ancrod, or reptilase, plasminogen activation did not occur.

Incubation of plasma FSF with thrombin, ancrod, and reptilase. Fig. 7 shows the SDS-gel patterns of reduced samples of plasma FSF after incubation with the various enzymes. As previously reported (34), gel a shows the overlap of the $a$ and $b$-chains of reduced plasma FSF zymogen. Gel $b$ shows that with activation by thrombin the $a$-chain decreases in molecular weight and is then designated $a^{\prime}$-chain. Gel $c$ clearly shows that ancrod 1 does not activate plasma FSF. Gel $d$ shows

TABLE I

Clotting Times of Citrated or Heparinized Plasma

\begin{tabular}{ccc}
\hline & \multicolumn{2}{c}{ Clotting times } \\
\cline { 2 - 3 } Enzyme & $\begin{array}{c}\text { Citrated } \\
\text { plasma }\end{array}$ & $\begin{array}{c}\text { Heparinized } \\
\text { plasma }\end{array}$ \\
\hline Thrombin, human & sec & sec \\
Reptilase & 50 & No clot at $8 \mathrm{hr}$ \\
Ancrod 1 & 165 & 170 \\
Ancrod 2 & 60 & 60 \\
Ancrod 3 & 150 & 160 \\
& 10 & 10 \\
\hline
\end{tabular}

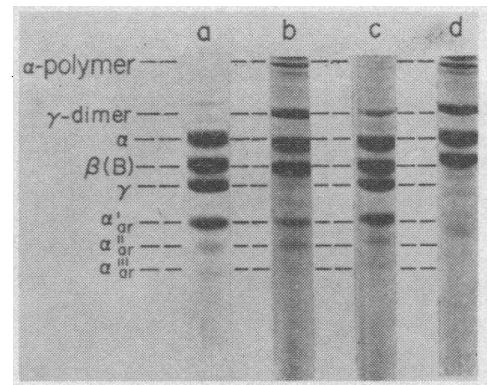

FIgURE 5 Reduced SDS-gel electrophoretic patterns of fibrin formed from heparinized plasma by ancrod 1 (gel $a$ ), ancrod 2 (gel $b$ ), ancrod 3 (gel $c$ ), and reptilase (gel $d$ ).

that a small amount of activation occurred with reptilase and gel $e$ shows what appears to be complete FSF activation by ancrod 2 . In the putrescine ${ }^{14} \mathrm{C}$ assay (37, 38 ), the degree of FSF activation by these enzymes paralleled the amount of $a^{\prime}$-chain formation as shown on the SDS gels. While frequently not appreciated (27), it should be noted that neither thrombin, reptilase, nor the ancrod 2 and 3 preparations require calcium for the activation of FSF. However ionized calcium is required by activated FSF as a cofactor during the catalysis of $\epsilon(\gamma$-glutamyl)-lysine cross-link formation between fibrin monomers (45).

Susceptibility of fibrin formed by thrombin, ancrod, and reptilase to plasmin degradation. Fibrin was allowed to form for different periods of time after the addition of ancrod 1, reptilase, or thrombin to a fibrinogen solution which contained contaminant FSF and plasminogen. At the end of each time period, a trace quantity of urokinase was added to each fibrin clot and the time of complete lysis was recorded. Fig. 8 shows a marked increase in susceptibility of ancrod clots to plasmin digestion and this correlated well with the degradation of the $\alpha$-chains by ancrod. The flattening of the lysis curve occurred at a time when approximately $75 \%$ of the $\alpha$-chains had been degraded. On the other hand, only a slightly increased tendency to lyse with duration of clotting was observed for fibrin formed by reptilase.

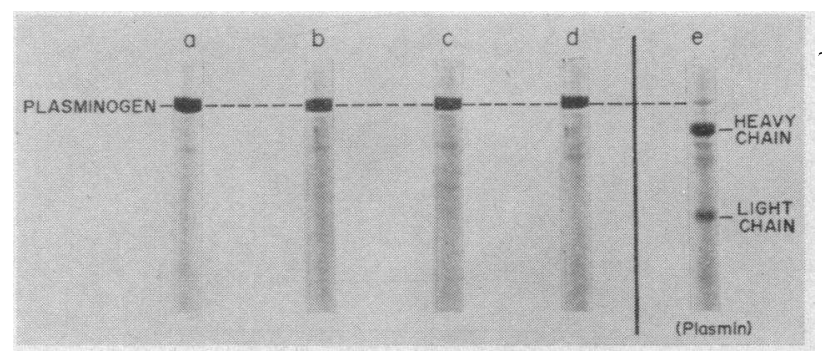

FIGURE 6 Reduced SDS-gel electrophoretic patterns of plasminogen (gel $a$ ); plasminogen incubated with thrombin (gel $b$ ), reptilase (gel $c$ ) or ancrod 1 (gel $d$ ), and plasminogen activated to plasmin by urokinase ( gel $e$ ). 


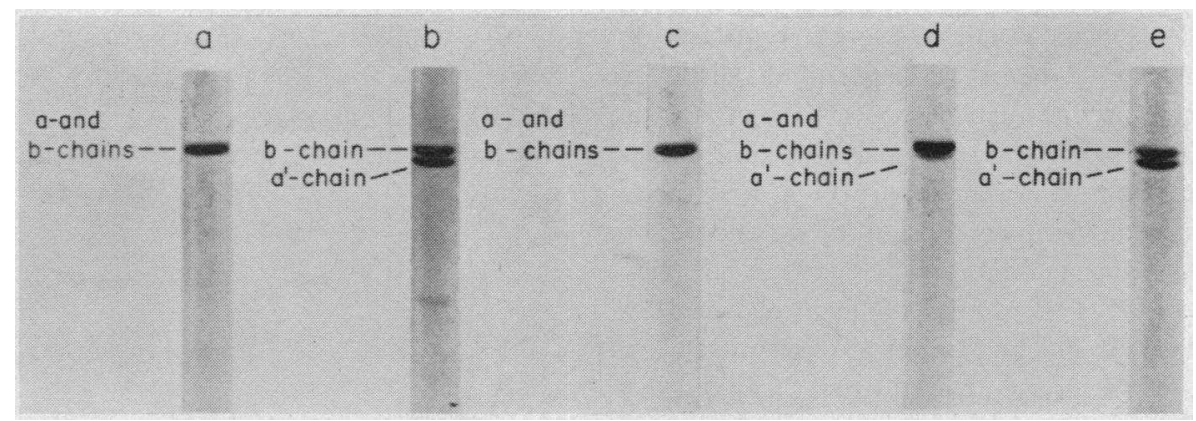

FIgURE 7 Reduced SDS-gel electrophoretic patterns of purified FSF. Gel $a$ shows the overlapping mobilities of the $a$ - and $b$-chains of plasma FSF zymogen. Gel $b$ shows the drop in molecular weight of the $a$-chain to give the $a^{\prime}$-chain when FSF is activated by thrombin. Gel $c$ shows that ancrod 1 does not cause FSF activation as evidenced by the absence of $a^{\prime}$-chain. Gel $d$ shows a small amount of $a^{\prime}$-chain when plasma FSF is incubated with reptilase. Gel $e$ shows essentially complete FSF activation by ancrod 2 .

Cross-linked fibrin formed in response to thrombin showed a decreased susceptibility to lysis by plasmin over the $8 \mathrm{hr}$ time course. It should be noted that the first point shown on the thrombin curve is soluble fibrin and is designated as zero time since it contains no crosslinks. In accord with an earlier suggestion (35), those fibrin clots containing maximal $\alpha$-polymer formation (at $2 \mathrm{hr}$ ) were the most resistant to lysis by plasmin.

\section{DISCUSSION}

Human fibrinogen can be represented by the subunit polypeptide formula, $(\alpha[\mathrm{A}] \beta[\mathrm{B}] \gamma)_{2}$, where $\mathrm{A}$ and $\mathrm{B}$ represent the small fibrinopeptides cleaved by thrombin to give rise to fibrin monomers, $(\alpha \beta \gamma)_{2}$. These monomers then align through noncovalent interactions to form a fibrin clot that is readily soluble in dispersing agents such as dilute acids, $5 \mathrm{~m}$ urea or $1 \%$ SDS. In the presence of calcium ion and FSF which has been activated by thrombin, covalent cross-links are formed between fibrin monomers. Each fibrin monomer contains ap-

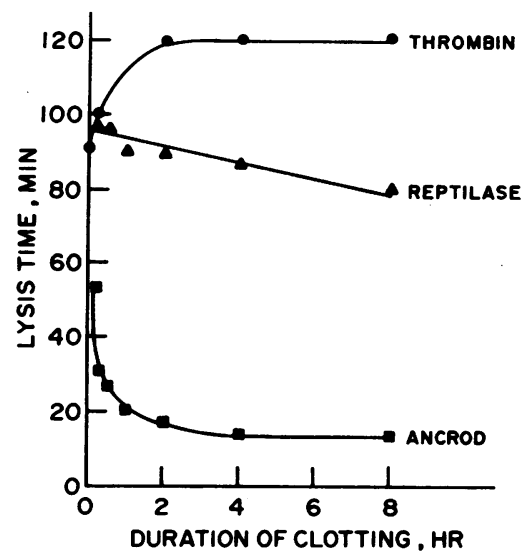

FIGURE 8 Relationship of lysis time to the duration of fibrin formation by thrombin, reptilase, and ancrod 1 . proximately four to six such potential cross-links sites (46). Initially a pair of cross-links are rapidly formed between $\gamma$-chains of different fibrin monomers to give rise to $\gamma$-dimer formation; more slowly, several $\alpha$-chains of different fibrin monomers are cross-linked to give rise to $\alpha$-polymer formation (33). As $\alpha$-polymerization progresses, the fibrin becomes completely insoluble in the above solvents and is then termed fully cross-linked fibrin.

Unlike thrombin, ancrod and reptilase are reported to cleave only fibrinopeptide $A$ from fibrinogen; in addition ancrod partially degrades fibrinopeptide A (22-24). Neither cleaves fibrinopeptide B, but despite this, fibrin formation still occurs rapidly. In vivo such fibrin is rapidly cleared and this has been attributed to lysis by plasmin $(30,47)$, since no further direct proteolytic effect of ancrod on fibrin could be demonstrated $(22,24$, 29 ), and to phagocytosis of fibrin by the reticuloendothelial system (31). However, it recently has been shown that ancrod itself definitely degrades the $\alpha$-chains of monomeric fibrin to yield approximately 38,000 and 33,000 mol wt cleavage products (26-28), the latter of which appears to undergo further degradation by ancrod. None of these cleavage products were seen during the degradation of either fibrinogen or fibrin by plasmin $(42,43)$. Our data clearly indicate that in the presence of FSF, fibrin formed by ancrod is markedly more susceptible to plasmin degradation than fibrin formed by thrombin. This usually has been attributed solely to the fact that ancrod-formed fibrin is noncross-linked (24, 29,47 ), since it has been shown that urea-soluble, noncross-linked clots are less resistant to lysis than crosslinked clots $(48,49)$. In accord with these observations, results shown in Fig. 8 clearly demonstrate that by 2 $\mathrm{hr}$, cross-linked fibrin has developed maximal resistance to lysis and it is at this time that $\alpha$-polymerization is essentially complete (33). As recently suggested (35), it 
appears that $\alpha$-polymer formation makes fibrin resistant to plasmin degradation. Although previously hypothesized $(1,14,50)$, the possibility than ancrod itself significantly degraded fibrin monomers was not supported by experimental evidence and was discounted in one study (29). In Fig. 8, the time at which ancrod-formed fibrin was maximally susceptible to lysis by plasmin correlated well with the cleavage of $\alpha$-chains by ancrod as shown in the SDS-gel electrophoretic patterns of Fig. 1. In view of the observation that ancrod extensively degrades the $\alpha$-chains of fibrin monomers and does not activate FSF, it is of interest that the elastic modulus of thrombin-formed, noncross-linked fibrin, $(\alpha \beta \gamma)_{2}$, is about twice that of ancrod-formed fibrin (47) which likewise is noncross-linked and in addition, must contain some fraction of intact $\alpha$-chains. Thus its subunit formula might be written as $\left[(\alpha / x \beta(\mathrm{B}) \gamma]_{2}\right.$, where $x$ is some integer greater than one and the value of $\alpha / x$ is dependent on the duration of fibrin formation in response to ancrod. It is therefore suggested that the degradation of the $\alpha$-chains in ancrod-formed fibrin accounts for its having a reduced elastic modulus. Our demonstration that ancrod-formed fibrin, which in the case of ancrod 1 is noncross-linked and contains degraded $\alpha$-chains, is markedly susceptible to lysis has implications to the clinical use of these enzymes. It is suggested that the use of ancrod preparations which do not promote fibrin crosslinking is preferable, since noncross-liked fibrin is more susceptible to lysis than cross-linked fibrin. It would also appear that ancrod would be preferable to reptilase for use in vivo since, unlike the reptilase preparation, highly purified ancrod (ancrod 1) itself partially degrades fibrin monomers and does not promote their cross-linking. Thus the in vivo removal of fibrin formed in response to ancrod would be maximized.

The data shown in Fig. 6 emphasize that the effect of ancrod on $\alpha$-chains is not due to plasminogen activation by ancrod. Moreover, as mentioned earlier, the degradation products by ancrod differ in molecular weight from those seen when plasmin degrades fibrinogen or fibrin $(42,43)$. Some preparations of ancrod obviously contain a contaminant proteolytic enzyme which is capable of activating FSF and which, unlike thrombin, is not inhibited by heparin. Such a contaminant was present in ancrod 2 but on further purification of this preparation to ancrod 3, most of this activity was removed. Interestingly, ancrod 1, which did not cause FSF activation in the present study, has been the preparation used in most of the clinical trials to date.

It has recently been reported (2) that ancrod can digest the $\alpha$-polymer of cross-linked fibrin to give the same cleavage products as obtained from fibrin monomers; however, in our experiments this was not the case. While exposure of cross-linked fibrin to ancrod for $8 \mathrm{hr}$ did result in the appearance of a small amount of the 38,000 and 33,000 mol wt species, these could be readily explained by the disappearance of residual $\alpha$-chains which were not incorporated into the $\alpha$-polymer. With further exposure of cross-linked fibrin to ancrod for 24 $\mathrm{hr}$, the $\alpha$-polymer appeared to decrease slightly in intensity, but this was clearly due to plasmin degradation and was not caused by ancrod (43). These results are in accord with previous studies which showed that high concentrations of ancrod did not cause increased lysis of whole blood clots $(6,29)$. Moreover when ancrod was used in 10 patients with deep venous thrombosis (16), complete thrombolysis was seen in only one, which again suggested that ancrod does not have a lytic effect on preformed cross-linked fibrin. The in vivo studies of Olsen and Pitney (51) suggested that the disappearance rate of preformed pulmonary emboli in rabbits was enhanced when the animals were infused beforehand with ancrod. They observed necrosis and lack of organization on histologic study of the preformed autogenous emboli removed from the animals pretreated with ancrod. Most likely these changes resulted from the inability of normal cross-linked fibrin to form on the surface of the preformed emboli, or between the emboli and pulmonary artery endothelium.

The preparation of reptilase used in this study activated $\mathrm{FSF}$, but it was not possible to determine whether this was an inherent property of reptilase or whether this activity reflected the presence of a contaminant enzyme as in the case of the ancrod 2 and 3 preparations. In the present study, even extremely high reptilase concentrations did not cleave monomeric fibrin after removal of fibrinopeptide $A$ as seen in Figs. 2 and 3. The degradation products most easily seen on gel $c$ in Fig. 3 can be attributed to the effect of plasmin rather than reptilase, since they have mobilities identical with those products resulting from the digestion of fibrinogen by plasmin alone. Thus, it was not possible to confirm the data of Mattock and Esnouf (27) who suggested that reptilase, like ancrod, cleaved fibrin to yield a $39,000 \mathrm{~mol}$ wt species. Under the conditions employed in this present study, reptilase-formed fibrin showed only a small change in susceptibility to lysis with increased exposure to reptilase. Of particular note, the initial fibrin lysis time was not greatly different from that seen for thrombin clots. While the work of Kwaan and Barlow $(52,53)$ indicated that reptilase fibrin is more susceptible to lysis by plasmin than that formed by ancrod or thrombin, details of their experimental methods are not yet available and thus cannot be compared with the present study. It is possible that the ancrod preparation which they used partially activated FSF and thereby promoted some cross-linked fibrin formation. Furthermore if the $\alpha(\mathrm{A})$ chains of their fibrinogen substrate were already par- 
tially degraded by contaminating plasmin as is frequently found (42), no $\alpha$-polymerization would occur and the lysis times for reptilase-formed fibrin would approximate those of ancrod-formed fibrin. Our present studies do not clarify the in vivo mechanisms of reptilase therapy; however, our data clearly show that reptilase activates FSF and in the presence of calcium promotes cross-linked fibrin formation which is in accord with the observations of other investigators (25). Thus, it would seem that reptilase-formed fibrin in the microcirculation would be fully cross-linked and hence very similar to thrombin clots formed during diffuse intravascular coagulation except that, unlike thrombin, reptilase does not appear to induce platelet interactions (10). Moreover, our data indicate that despite a slight trend towards increased susceptibility to lysis with longer duration of clotting, reptilase clots are much more resistant to lysis than are ancrod clots.

On the basis of our data and results from other studies, it is possible to postulate the following sequence of events to account for the anticoagulant effect of ancrod in vivo: (a) the administration of ancrod results in the formation of fibrin clots in the microcirculation, particularly in the kidney, lungs, liver, and bone marrow (54); (b) these clots, however, contain noncross-linked fibrin and furthermore become defective as the $\alpha$-chains continue to be significantly degraded by ancrod; $(c)$ the activation of plasminogen to plasmin occurs in a manner analogous to that observed when intravascular clotting occurs as a result of thrombin generation $(12,30,55)$; $(d)$ the resultant high level of plasmin then digests ancrod-formed fibrin at a much more rapid rate than thrombin-formed fibrin, and this can be attributed to the fact that such fibrin is noncross-linked and in addition, has already been significantly degraded by ancrod; $(e)$ the generation of fibrin split products as well as the fibrinogenopenia produces a hypocoagulable state $(56,57)$. In general, the results of clinical studies support these mechanisms $(6,14)$. In such studies, patients receiving ancrod showed a marked decrease in plasminogen concentration, which often approached zero after about 10 $\mathrm{hr}$ from the onset of ancrod administration. Also at this time, these investigators found that fibrin degradation products had usually reached a peak value. While the mechanism by which the fibrinolytic system becomes activated is not understood, it is clear that ancrod does not activate plasminogen as has been shown in this study by direct observations of ancrod action on purified plasminogen. Despite what mechanism may be invoked to explain the rapid activation of plasminogen to plasmin during intravascular clotting, it is apparent that ancrod clots are strikingly susceptible to plasmin degradation as shown in Fig. 8. Besides digestion by plasmin, phagocytosis of fibrin by the reticuloendothelial system repre- sents a second important method by which fibrin is removed from the microcirculation (31). However whether or not the defective, noncross-linked fibrin formed by ancrod is more susceptible to phagocytosis by the reticuloendothelial system is conjectural and must await further study.

\section{ACKNOWLEDGMENTS}

The authors wish to thank Doctors Grant H. Barlow and Joseph F. Donahoe for supplying the ancrod and reptilase preparations used in these studies.

These studies were supported by a Clinical Investigatorship, Veterans Administration, and research grants from the National Heart and Lung Institute (HE 06400), and the National Institute of Neurological Diseases and Stroke (NS 06233).

\section{REFERENCES}

1. Esnouf, M. P., and G. W. Tunnah. 1967. The isolation and properties of the thrombin-like activity from Ancistrodon rhodostoma venom. Br. J. Haematol. 13: 581.

2. Klobusitzky, D., and P. Konig. 1936. Biochemische studien uber die gifte der schlangengattung bothrops. IV. Mitteifung: die Wirkung der gerinnungs fordernden Substanz in vivo. Arch. Exp. Pathol. Pharmakol. 182: 387.

3. Chan, K. E., and H. A. Reid. 1964. Fibrinolysis and the defibrination syndrome of Malayan viper bite. Lancet. $1: 461$.

4. Ashford, A., J. W. Ross, and P. Southgate. 1968. Pharmacology and toxicology of a defibrinating substance from Malayan pit viper venom. Lancet. 1: 486.

5. Bell, W. R., W. R. Pitney, and J. F. Goodwin. 1968. Therapeutic defibrination in the treatment of thrombotic disease. Lancet. 1: 490 .

6. Pitney, W. R., W. R. Bell, and G. Bolton. 1969. Blood fibrinolytic activity during arvin therapy. Br. J. Hacmatol. 16: 165 .

7. Pitney, W. R. 1971. An appraisal of therapeutic defibrination. Thromb. Diath. Haemorrh. 45(Suppl.) : 43.

8. Sharp, A. A. 1971. Clinical use of arvin. Thromb. Diath. Haemorrh. 45 (Suppl.) : 69.

9. Blombäck, B., M. Blombäck, N. Egberg, H. Johnson, S. A. Johansson, S. Nordström, and P. Olsson. 1971. Clinical and experimental studies on reptilase. The 19th Annual Symposium on Blood: Thrombolytic Therapy. Wayne State University School of Medicine, Detroit. 33.

10 B!ombäck, M., N. Egberg, E. Gruder, S.-A. Johansson, H. Johnsson, S. E. G. Nilsson, and B. Blombäch. 1971. Treatment of thrombotic disorders with reptilase. Thromb. Diath. Haemorrh. 45(Suppl.) : 51.

11. Reid, H. A., K. E. Chan, and P. C. Thean. 1963. Prolonged coagulation defect (defibrination syndrome) in Malayan viper bite. Lancet. 1: 621.

12. Regoeczi, E., J. Gergely, and A. S. McFarlane. 1966. In vivo effects of Agkistrodon rhodostoma venom: studies with fibrinogen-131 I. J. Clin. Invest. 45: 1202.

13. Reid, H. A., and K. E. Chan. 1968. The paradox in therapeutic defibrination. Lancet. 1: 485.

14. Sharp, A. A., B. A. Warren, A. M. Paxton, and M. J. Allington. 1968. Anticoagulant therapy with a purified fraction of Malayan pit viper venom. Lancet. 1: 493. 
15. Bell, W. R., G. Bolton, and W. R. Pitney. 1968. The effect of arvin on blood coagulation factors. $\mathrm{Br}$. J. Haematol. 15 : 589.

16. Kakkar, V. V., C. Flanc, C. T. Howe, M. O'Shea, and P. T. Flute. 1969. Treatment of deep vein thrombosis. A trial of heparin, streptokinase and arvin. Br. Med. J. $1: 806$.

17. Pitney, W. R., C. M. Oakley, and J. F. Goodwin. 1970. Therapeutic defibrination with arvin. Am. Heart J. 80: 144.

18. Deutsch, E. 1955. Blutgerinnungsfaktoren. Franz Deuticke, Vienna. 208.

19. Blombäck, B., M. Blombäck, and I. M. Nilsson. 1957. Coagulation studies on "reptilase," an extract of the venom from Bothrops jararaca. Thromb. Diath. Hacmorrh. $1: 76$.

20. Chan, K. E., C. R. Rizza, and M. P. Henderson. 1965. A study of the coagulant properties of Malayan pit-viper venom. Br. J. Haematol. 11: 646.

21. Blombäck, B. 1958. Studies on the action of thrombic enzymes on bovine fibrinogen as measured by $\mathrm{N}$-terminal analysis. Ark. Kem. 12: 321 .

22. Ewart, M. R., M. W. C. Hatton, J. M. Basford, and K. S. Dodgson. 1970. The proteolytic action of arvin on human fibrinogen. Biochem. J. 118: 603.

23. Holleman, W. H., and L. J. Coen. 1970. Characterization of peptides released from human fibrinogen by arvin. Biochim. Biophy's. Acta. 200 : 587.

24. Barlow, G. H., W. H. Holleman, and L. Lorand. 1970. The action of arvin on fibrin stabilizing factor (factor XIII). Res. Commun. Chcm. Pathol. Pharmacol. 1: 39.

25. Kopeć, M., Z. S. Latao, M. Stahl, and Z. Wegrzynowicz. 1969. The effect of proteolytic enzymes on fibrin stabilizing factor. Biochim. Biophys. Acta. 181: 437.

26. Pizzo, S. V., M. L. Schwartz, R. L. Hill, and P. A. McKee. 1971. A direct proteolytic effect on soluble fibrin by arvin. Clin. Res. 19: 667.

27. Mattock, P., and M. P. Esnouf. 1971. Differences in the subunit structure of human fibrin formed by the action of arvin, reptilase and thrombin. Nat. New Biol. 233: 277.

28. Pizzo, S. V., M. L. Schwarz, R. L. Hill, and P. A. McKee. 1972. Fibrin destruction by arvin-the mechanism of arvin anticoagulation. Clin. Res. 20: 46. (Abstr.)

29. Turpie. A. G. G., C. R. M. Prentice, G. P. McNicol, and A. S. Douglas. 1971. In-vitro studies with ancrod ('Arvin'). Br. J. Haematol. $20: 217$.

30. Rubenberg, M. L., B. S. Bull, E. Regoeczi, J. V. Dacie, and M. C. Brain. 1967. Experimental production of microangiopathic haemolytic anaemia in vivo. Lancet. 2: 1121 .

31. Lee, L., P. H. Prose, and M. H. Cohen. 1966. The role of the reticuloendothelial system in diffuse, low grade intravascular coagulation. Thromb. Diath. Haemorrh. 20 (Suppl.) : 87.

32. Blombäck, B., and M. Blombäck. 1956. Purification of human and bovine fibrinogen. Ark. Kem. 10: 415.

33. McKee, P. A., P. Mattock, and R. L. Hill. 1970. Subunit structure of human fibrinogen, soluble fibrin and cross-linked insoluble fibrin. Proc. Natl. Acad. Sci. U.S.A. $66: 738$.

34. Schwartz, M. L., S. V. Pizzo, R. L. Hill, and P. A. McKee. 1971. The subunit structures of human plasma and platelet factor XIII (fibrin-stabilizing factor). $J$. Biol. Chem. 246: 5851.
35. Schwartz, M. L., S. V. Pizzo, R. L. Hill, and P. A. McKee. 1971. The effect of fibrin-stabilizing factor on the subunit structure of human fibrin. J. Clin. Invest. 50: 1506 .

36. Deutsch, D. G., and E. T. Mertz. 1970. Plasminogen: purification from human plasma by affinity chromatography. Science (Wash. D. C.). 170: 1095.

37. Dvilansky, A., A. F. H. Britten, and A. G. Loewy. 1970. Factor XIII assay by an isotope method. I. Factor XIII (transamidase) in plasma, serum, leucocytes, erythrocytes and platelets and evaluation of screening tests of clot solubility. Br. J. Haematol. 18: 399.

38. Dvilansky, A., A. F. H. Britten, and A. G. Loewy. 1970. Factor XIII assay by an isotope method. II. Heparin inhibition of factor XIII activation. Thromb. Diath. Haemorrh. 24: 256.

39. Weber, K., and M. Osborn. 1969. The reliability of molecular weight determinations by dodecyl sulfatepolyacrylamide gel electrophoresis. J. Biol. Chem. 244: 4406.

40. Dunker, A. K., and R. R. Rueckert. 1969. Observations on molecular weight determinations on polyacrylamide gel. J. Biol. Chcm. 244 : 5074.

41. Huseby, R. M., and N. U. Bang. 1971. Fibrinogen. In Thrombosis and Bleeding Disorders. Theory and Methods. N. U. Bang. F. K. Beller, E. Deutsch, and E. F. Mamnen, editors. Academic Press, Inc., New York. 245.

42. Pizzo, S. V., M. L. Schwartz, R. L. Hill, and P. A. McKee. 1972. The effect of plasmin on the subunit structure of human fibrinogen. J. Biol. Chem. 247: 636.

43. Pizzo, S. V., M. L. Schwartz, R. L. Hill, and P. A. McKee. 1972. Comparison of the subunit structures of plasmin digested fibrinogen and fibrin. Fed. Proc. 31: 261.

44. Barlow, G. H., L. Summaria, and K. C. Robbins. 1969. Molecular weight studies on human plasminogen and plasmin at the microgram level. J. Biol. Chem. 244: 1138.

45. Tyler, H. M. 1970. Studies on the activation of purified human factor XIII. Biochim. Biophys. Acta. 222: 396.

46. Pisano, J. J., J. S. Finlayson, M. P. Peyton, and Y. Nagai. 1971. $\epsilon$ ( $\gamma$-glutamyl) lysine in fibrin: lack of crosslink formation in factor XIII deficiency. Proc. Natl. Acad. Sci. U. S. A. 68: 770.

47. Lorand, L. 1971. Discussion of Report by Kwaan and Barlow. (Kwaan, H. C., and G. H. Barlow. 1971. The mechanism of action of a coagulant fraction of malayan pit viper venom, arvin, and reptilase. Thromb. Diath. Haemorrh. 45[Suppl.] : 63.) Thromb. Diath. Haemorrh. 45 (Suppl.) : 74.

48. Gormsen, J., and U. Sivertsen. 1964. The effect of sulfhydroxylinhibitors and glycine derivatives on fibrin polymerization and the physical strength of fibrin in plasma. Thromb. Diath. Haemorrh. 11: 454.

49. Gottleib, S. F., D. R. Celander, and M. M. Guest. 1959. Effect of fibrin-stabilizing factor on susceptibility of clots to fibrinolysis. Fed. Proc. 18: 58.

50. Rodriguez-Erdmann, F., C. B. Carpenter, and E. G. Galvanek. 1971. Experimental dysfibrinogenemia: in vivo studies with arvin. Blood J. Hematol. 37: 664.

51. Olsen, E. G. J., and W. R. Pitney. 1969. The effect of arvin on experimental pulmonary embolism in the rabbit. Br. J. Haematol. $17: 425$.

52. Kwaan, H. C., and G. H. Barlow. 1971. The mecha- 
nism of action of arvin and reptilase. The 19th Annual Symposium on Blood: Thrombolytic Therapy. Thromb. Diath. Haemorrh. 47(Suppl.) : 361.

53. Kwaan, H. C., and G. H. Barlow. 1971. The mechanism of action of a coagulant fraction of malayan pit viper venom, arvin and of reptilase. Thromb. Diath. Haemorrh. 45 (Suppl.) : 63.

54. Regoeczi, E., and M. C. Brain. 1969. Organ distribution of fibrin in disseminated intravascular coagulation. $\mathrm{Br}$. J. Haematol. 17 : 73.
55. Bang, N. U., P. C. Harpel, and F. Strueli. 1964. Hypofibrinogenemic hemorrhage. Clin. Obstet. Gynecol. 7: 286.

56. Regoeczi, E. 1971. Interference of lysed fibrin with coagulation: a quantifying approach using isotopic techniques. Br. J. Haematol. $21: 209$.

57. Marder, V. J., and N. R. Shulman. 1969. High molecular weight derivatives of human fibrinogen produced by plasmin. II. Mechanism of their anticoagulant activity. J. Biol. Chem. 244 : 2120. 